\title{
Quantifying the likelihood of a continued global warming hiatus
}

C.D. Roberts ${ }^{1}$, M.D. Palmer ${ }^{1}$, D. McNeall ${ }^{1}, \&$ M. Collins ${ }^{2}$

${ }^{1}$ Met Office Hadley Centre, Exeter, UK.

${ }^{2}$ University of Exeter, UK.

Since the end of the 20th century, global mean surface temperature (GMST) has not risen as rapidly as predicted by global climate models $(\mathrm{GCMs})^{1-3}$. This discrepancy has become known as the global warming 'hiatus' and a variety of mechanisms ${ }^{1,4-17}$ have been proposed to explain the observed slowdown in warming. Focussing on internally generated variability, we use an observationally-constrained ensemble of GCMs and a statistical approach to evaluate the expected frequency and characteristics of global warming hiatus periods and their likelihood of future continuation. Given an expected contemporary surface warming rate of about $0.2 \mathrm{~K} /$ decade from GCMs, our estimated probability for a 10-year warming hiatus due to internal variability is $\sim 10 \%$, but less than $1 \%$ for a 20 -year hiatus. However, although the absolute probability of a 20-year hiatus is small, the probability that an existing 15-year hiatus will continue another five years is up to $25 \%$. Therefore, we should not be surprised if the present hiatus continued until the end of the current decade. Finally, following the termination of a hiatus, we show that there is an increased likelihood of accelerated global warming associated with release of heat from the sub-surface ocean and a reversal of the phase of decadal variability in the Pacific Ocean. 
The unexpectedly modest rise in GMST over the last decade or so, often referred to as the global warming 'hiatus', has attracted considerable interest from the scientific community and wider public ${ }^{1-3,8,18}$. While recent observational studies have shown that incomplete spatial sampling may play a role ${ }^{19}$, this cannot account for the discrepancy between the observed trend $(-0.04$ to $0.04 \mathrm{~K} /$ decade, for the decade ending in 2013) and the central estimate from climate models (0.2 K/decade) (fig. 1). However, several studies have shown that hiatus decades are not inconsistent with our expectations of internal climate variability $1,8,10,11,20$ and do not necessarily imply a reduction in the rate of energy accumulation in the Earth system ${ }^{10,21,22}$.

The latest IPCC assessment report ${ }^{2}$ attributed the hiatus to some combination of (i) external climatic forcings that are not adequately represented in model simulations of the recent period and (ii) the internal climate variability that is intrinsic to individual model simulations but largely absent from the multi-model mean. Mechanisms proposed to explain the hiatus include aerosol emissions from modest volcanic eruptions $s^{6,12,13,16,23}$, a delayed response to the Mount Pinatubo eruption ${ }^{24}$, the unexpectedly prolonged solar minimum ${ }^{7,14,24}$, stratospheric water vapour changes ${ }^{15}$, increases in anthropogenic sulfate aerosol emissions ${ }^{14,16,25}$, internal decadal variability in the Pacific and/or high-latitude oceans ${ }^{9-11,26,27}$, and externally forced and/or internally generated wind-driven rearrangement of heat in the oceans ${ }^{4,5}$. Several studies have previously commented on the likelihood of a warming hiatus and the potential for a subsequent accelerated warming $5,8,17,20,27,28$; however, none have considered the likelihood of the present hiatus continuing into the future using the framework of conditional probabilities. 
In the present work, we consider how long the observed hiatus might last due to internal variability alone and characterise both the spatial patterns of surface temperature change, and the likelihood of accelerated GMST rise, following the termination of a hiatus. The results of our study are based on 23 multi-century preindustrial control simulations from CMIP5 (see methods). These physically-based model simulations of climate variability are combined with statistical models (ARMA models, see methods) to quantify both absolute and conditional probabilities of a hiatus event continuing for a given number of years. In addition, we repeat our analysis with a subset of climate models that have the most realistic representation of Pacific variability-an area of the ocean that has played a key role in the observed hiatus ${ }^{5,9}$.

We assume that the time evolution of GMST can be considered a linear combination of a 'signal' due to external climate forcings superimposed on 'noise' that is consistent with variability in preindustrial control simulations. In addition, we assume that the rate of warming due to external forcings can be considered constant on decadal time scales. These assumptions are reasonable when considering the evolution of GMST during the early 21 st century (see supp. methods). In this paradigm, the probability that internal variability will offset a warming rate of, e.g. $0.2 \mathrm{~K} / \mathrm{dec}$ ade for the current climate, is the same as the probability that internal variability will cause a global temperature trend $<-0.2 \mathrm{~K} /$ decade in a preindustrial control experiment. We note that if greenhouse gas concentrations continue to increase during the 21 st Century, then periods of zero warming will become less likely in the future ${ }^{28}$. However, periods with anomalous rates of cooling/warming will continue to arise from internal variability and it is on these events that we focus our analysis. We use the following terminology: (i) 'Hiatus' refers to a period of suppressed 
warming (GMST change), or even zero trend or cooling, when a forced warming trend is expected. Assuming linearity, it can be equated with an anomalous cooling in a preindustrial control simulation that exceeds some threshold value, superimposed on a forced warming trend. (ii) 'Continued hiatus' refers to an existing hiatus that experiences continued muted GMST response of the same (or greater) magnitude. (iii) 'Accelerated warming' refers to a period of anomalous warming that exceeds that which would be expected from the forced signal. Such a trend may be equated with a magnitude that exceeds the magnitude of cooling during a preceding hiatus in a preindustrial control simulation as in our definition of a hiatus.

We estimate the multi-model mean probability (see methods) of GMST cooling trends of -0.1 to $-0.3 \mathrm{~K} /$ decade - sufficient to offset a long-term warming rate of the same magnitude - arising from internal variability as a function of trend length (fig 2a). This range of trend magnitudes is chosen to account for uncertainty in the transient climate response (TCR) to external forcings (see methods). Given an expected warming rate of $0.2 \mathrm{~K} /$ decade, our multi-model probability for a 10-year warming hiatus due to internal variability is $9 \%$ with a range across models of $0-17$ $\%$ (table 1, fig S1). For a 20-year hiatus (i.e. a 20-year period with a trend $<-0.2 \mathrm{~K} / \mathrm{decade}$ ) the multi-model probability is $<1 \%$ (fig. $2 a$ ) and the range across models is $0-2 \%$ (table 1 ). The range of probabilities across models is a consequence of differences in the characteristics of simulated internal GMST variability (fig. S3). Notably, a 20-year hiatus due to internal variability alone is very unlikely, but is not outside the range of internal variability as simulated by GCMs (fig. S1-S2). 
However, we argue that the expected frequency of a hiatus occurring in any given period is not the most useful quantity for communicating the chance that the current warming hiatus will extend into the future. Instead, we propose the use of conditional probabilities to evaluate the fraction of hiatus events of a given length that will continue for a specified period (fig. 2b). For example, if internal variability has offset warming of $0.2 \mathrm{~K} /$ decade for a period of 15 years, our multi-model mean estimate of the fraction of events that that will continue to offset warming for another 5 years is $16 \%$, with a multi-model range of $0-29 \%$ (table 1 ). In addition, for trend lengths of 5 to 20 years, the probabilities in fig. $2 \mathrm{~b}$ are surprisingly insensitive to the existing trend length. This is a consequence of the year-to-year persistence of GMST anomalies associated with internal variability (fig S3). If the real-world behaviour of internal GMST variability can be approximated by GCMs, our analysis indicates that there is a substantial probability of the current hiatus continuing for 5 more years. Failure to adequately communicate this possibility could lead to allegations of overconfidence in GCM projections, especially if the existing hiatus continues until 2020 and beyond.

To investigate the spatial changes associated with hiatus events in models, we identify 128 decades with global cooling less than $-0.2 \mathrm{~K} /$ decade from 23 CMIP5 preindustrial control simulations. The mean characteristics of these events share many of the previously identified features of warming slow-downs in observations $s^{4,5,9}$ and models ${ }^{10,11}$, including a pattern of surface temperature change resembling the negative phase of the Pacific Decadal Oscillation (PDO), accelerated Pacific trade winds and spin-up of the sub-tropical gyres, sub-surface warming in regions of thermocline convergence (fig. S4), and increased ocean heat uptake beneath the ocean mixed layer 
(fig. 4).

However, we emphasize that the composite mean is an inadequate description of any single model or event. Single-model composites and individual events show marked differences in the magnitude and patterns of near-surface temperature change (fig. S5), the locations and magnitude of heat convergence in the thermocline and regions of deep water formation (figs S6-S7), the relative importance of ocean heat redistribution and top-of-atmosphere radiation (TOA) imbalance (fig S8), and the patterns and magnitudes of near-surface wind anomalies (fig S5). For example, as previously reported by ref $\left({ }^{10}\right)$, hiatus decades in CCSM4 are characterised by a PDO-like pattern of near surface temperature change, increased deep ocean heat uptake (and associated heat export from the near-surface), and no significant changes in TOA. In contrast, hiatus decades in GFDLCM3 are characterised by strong surface cooling and accelerated westerly winds over the Southern Ocean, a large contribution to cooling from TOA imbalance, and no significant changes in deep ocean heat uptake. These differences are a powerful motivator for the application of observational constraints that allow us to identify models that have the best representation of internal climate variability.

The evaluation of internal GMST variability by comparison with historical observations is complicated by the confounding influence of uncertain climate forcings and variable model responses ${ }^{2}$. However, many studies have emphasized the importance of the tropical Pacific for the evolution of $\mathrm{GMST}^{5,9,29,30}$. To examine the sensitivity of our results to model deficiencies in simulated internal climate variability, we use a simple metric to identify a subset of models that most 
accurately simulate the magnitude of tropical Pacific sea surface temperature (SST) variability (fig 3; see methods for details of the applied constraint). Following the application of our constraint, the absolute and conditional probabilities of a hiatus event continuing for a given number of years are very similar (fig. $2 \mathrm{c}$ and 2 d, table 1 ), although the probability of events lasting longer than 20 years is reduced due to the exclusion of some models that have large amplitude GMST variability on multi-decadal to centennial time scales.

Finally, we use our constrained ensemble to evaluate the climatic impacts in the periods that follow hiatus decades. Although we have emphasized the possibility of an existing hiatus continuing into the future, there is also an increased risk of 'accelerated warming' following a hiatus (fig 4b). We find that a 5-year period of accelerated warming $>0.2 \mathrm{~K} /$ decade is 1.7 (model range of 1.3 - 2.1) times more likely to occur when starting from the last year of a hiatus decade $(<-0.2 \mathrm{~K} /$ decade) (fig 4b) . Alternatively, a 5-year 'accelerated warming' period is 2.0 (model range of 1.6 - 2.4) times more likely to occur when we only consider trends starting the last year of 'terminated' hiatus decades (i.e. those that do not continue another five years into the future).

Continued hiatus periods are associated with heat uptake by the sub-surface ocean (fig 4a) and a composite mean pattern of surface temperature change similar to that in hiatus decades (fig 4c). In contrast, accelerated warming periods are associated with the release of $\sim 0.2 \mathrm{~W} / \mathrm{m}^{2}$ of heat from the sub-surface ocean (fig 4a), a pattern of warming that approximates a mirror image of surface temperature trends during hiatus periods (fig 4d), and a strong shift towards the positive phase of the PDO (fig 4a). In addition, there is some consensus ( $>2 / 3$ events) that periods of 
accelerated warming following global cooling decades will be associated with warming across South America, Australia, Africa, South East Asia, and the Arctic.

One of the notable discrepancies between recently observed surface temperature trends and the features of 'hiatus' decades in model simulations ${ }^{9-11}$ (fig S4) is in the sign of temperature change over the Arctic. Hiatus decades associated with internal variability in models generally exhibit cooling over the Arctic whereas recent observations ${ }^{19}$ indicate a strong warming. Our results indicate that, following the termination of the current global warming hiatus, internal climate variability may act to intensify rates of Arctic warming leading to increased climate stress on a region that is already particularly vulnerable to climate change.

Here, we have shown that a global warming hiatus could last 10-20 years or more due to internal variability alone. Although we found no systematic bias in the representation of tropical Pacific SST variability (fig 3), others have highlighted that a recent acceleration of equatorial Pacific trade winds is outside the range of variability simulated by CMIP5 models ${ }^{5}$. This difference was attributed to (i) models systematically underestimating internal variability and/or (ii) a role for external forcings in the recent hiatus. If either of these factors are important, we expect hiatus periods in the real world to last longer and/or be more extreme (i.e. offset more warming) than those due to internal variability in CMIP5 models. In addition, regardless of whether internal variability or external forcings have been the dominant driver of the observed warming hiatus, we emphasize that there is a substantial probability that internal variability of the climate system could offset warming until the end of the current decade. 


\section{Methods}

Observed temperature trends. We use the following observational data sets to estimate GMST trends: (i) 100 realizations of HadCRUT4 ${ }^{31}$ available from http://www.metoffice.gov.uk/hadobs/hadcrut4/.

(ii) Two versions of HadCRUT4 in which unobserved grid boxes are filled using either optimal interpolation or a hybrid method that incorporates satellite temperature data ${ }^{19}$ available from http://www-users.york.ac.uk/ kdc3/papers/coverage2013/series.html. (iii) GISTEMP 32 available from http://data.giss.nasa.gov/gistemp/. (iv) NOAA Merged Air Land and SST Anomalies data ${ }^{33}$ available from http://www.esrl.noaa.gov/psd/. Observed SST trends in the Niño 3.4 region are calculated using the Hadley Centre Sea Ice and Sea Surface Temperature gridded data set ${ }^{34}$ available from http://www.metoffice.gov.uk/hadobs/.

CMIP5 model data. We use data from simulations performed as part of phase 5 of the coupled climate model intercomparison project (CMIP5). CMIP5 is the primary modelling resource used in support of the Fifth Assessment Report of the Intergovernmental Panel on Climate change (IPCC AR5) and the contributing models represent the state-of-the-art in coupled climate simulations. Each model provides an estimate of the evolving ocean and atmosphere state in response to any imposed climate forcings and includes representation of the intrinsic variability generated by the coupled climate system.

Estimation of warming due to external forcings. To estimate background warming rates over the historical period, we use historical (up to 2005) and RCP4.5 (post 2005) scenarios from available CMIP5 models. We estimate uncertainty in the forced component of climate change by 
calculating single-model ensemble means for CMIP5 models with 3 or more historical scenario ensemble members, and applying a low-pass Butterworth filter with a 10-year cut-off. From 20042013, our estimates of background warming rates due to external forcings range from 0.11 to 0.28 $\mathrm{K} /$ decade. The thirteen models that match this constraint have a transient climate response (TCR, as estimated by $\operatorname{ref}\left({ }^{35}\right)$ ) to a doubling of $\mathrm{CO}_{2}$ in the range $1.5-2.5 \mathrm{~K}$ (c.f. the IPCC AR5 likely range of 1.0 to $2.5 \mathrm{~K}$ ). TCR represents a measure of the sensitivity of GMST rise to imposed greenhouse gas concentrations in the models such that those with larger TCR have a larger projected surface warming for a given climate change scenario; importantly, we find no significant relationship between model TCR and the characteristics of internal GMST variability (fig S9). This means that the impact of uncertainties in TCR can be considered independently from the impact of uncertainties in the representation of GMST variability.

Calculation of internal variability. To estimate internal variability in GMST and Niño SST indices we use CMIP5 pre-industrial control simulations and calculate annual mean diagnostics using data from the 23 models listed in table S1 retrieved from the CMIP5 archive (http://cmippcmdi.llnl.gov/cmip5/). All preindustrial control time series are linearly detrended to limit the impact of model drift.

Estimation of trend probabilities. Long time series are necessary for the estimation of probabilities conditional on the existence of a preceding event. For this reason, we use generic autoregressive moving-average (ARMA) models to generate 10,000-year long synthetic realizations of GMST variability that have the same auto-correlation characteristics as data from CMIP5 preindustrial control simulations. We fit ARMA models of the form 


$$
\left(1-\sum_{i=1}^{p} \varphi_{i} L^{i}\right) X_{t}=\left(1+\sum_{i=1}^{q} \theta_{i} L^{i}\right) \varepsilon_{t}
$$

to each detrended CMIP5 time series $\left(X_{t}\right)$, where $\varphi_{i}$ and $\theta_{i}$ are autoregression (AR) and moving-average (MA) coefficients at lag $i, p$ and $q$ are the order of AR and MA components, $L^{i}$ is the lag operator (defined such that $L^{i} X_{t}=X_{t-i}$ ), and $\varepsilon_{t}$ is Gaussian white noise with a variance of $\sigma^{2}$. Values of $p$ and $q$ are calculated by minimization of an Akaike information criterion as implemented in the forecast package of $R^{36}$. Trend probabilities are estimated by calculating linear least-squares trends for all overlapping trends of length $\mathrm{N}$ and then finding the fraction of trends with a slope coefficient less than or equal to a specified value.

Additional methodological details and supporting figures are included as Supplementary Information.

1. Easterling, D. R. \& Wehner, M. F. Is the climate warming or cooling? Geophysical Research Letters 36 (2009).

2. Flato, G. et al. Evaluation of climate models. Intergovernmental Panel on Climate Change, Working Group I Contribution to the IPCC Fifth Assessment Report (AR5)(Cambridge Univ Press, New York 741-866 (2013).

3. Fyfe, J. C., Gillett, N. P. \& Zwiers, F. W. Overestimated global warming over the past 20 years. Nature Climate Change 3, 767-769 (2013). 
4. Balmaseda, M. A., Trenberth, K. E. \& Källén, E. Distinctive climate signals in reanalysis of global ocean heat content. Geophysical Research Letters 40, 1754-1759 (2013).

5. England, M. H. et al. Recent intensification of wind-driven circulation in the pacific and the ongoing warming hiatus. Nature Climate Change 4, 222-227 (2014).

6. Haywood, J. M., Jones, A. \& Jones, G. S. The impact of volcanic eruptions in the period 2000-2013 on global mean temperature trends evaluated in the HadGEM2-ES climate model. Atmospheric Science Letters 15, 92-96 (2014).

7. Kaufmann, R. K., Kauppi, H., Mann, M. L. \& Stock, J. H. Reconciling anthropogenic climate change with observed temperature 1998-2008. Proceedings of the National Academy of Sciences 108, 11790-11793 (2011).

8. Knight, J. et al. Do global temperature trends over the last decade falsify climate predictions. Bulletin of the American Meteorological Society 90, S1-S196 (2009).

9. Kosaka, Y. \& Xie, S.-P. Recent global-warming hiatus tied to equatorial pacific surface cooling. Nature 501, 403-407 (2013).

10. Meehl, G. A., Arblaster, J. M., Fasullo, J. T., Hu, A. \& Trenberth, K. E. Model-based evidence of deep-ocean heat uptake during surface-temperature hiatus periods. Nature Climate Change 1, 360-364 (2011).

11. Meehl, G. A., Hu, A., Arblaster, J. M., Fasullo, J. \& Trenberth, K. E. Externally forced and internally generated decadal climate variability associated with the interdecadal pacific oscillation. Journal of Climate 26, 7298-7310 (2013). 
12. Neely, R. et al. Recent anthropogenic increases in SO2 from Asia have minimal impact on stratospheric aerosol. Geophysical Research Letters 40, 999-1004 (2013).

13. Santer, B. D. et al. Volcanic contribution to decadal changes in tropospheric temperature. Nature Geoscience 7, 185-189 (2014).

14. Schmidt, G. A., Shindell, D. T. \& Tsigaridis, K. Reconciling warming trends. Nature Geoscience 7, 158-160 (2014).

15. Solomon, S. et al. Contributions of stratospheric water vapor to decadal changes in the rate of global warming. Science 327, 1219-1223 (2010).

16. Solomon, S. et al. The persistently variable background stratospheric aerosol layer and global climate change. Science 333, 866-870 (2011).

17. Watanabe, M. et al. Strengthening of ocean heat uptake efficiency associated with the recent climate hiatus. Geophysical Research Letters 40, 3175-3179 (2013).

18. Hawkins, E., Edwards, T. \& McNeall, D. Pause for thought. Nature Climate change 4, 154156 (2014).

19. Cowtan, K. \& Way, R. G. Coverage bias in the HadCRUT4 temperature series and its impact on recent temperature trends. Quarterly Journal of the Royal Meteorological Society (2014).

20. Katsman, C. \& van Oldenborgh, G. J. Tracing the upper ocean's missing heat. Geophysical Research Letters 38 (2011). 
21. Palmer, M. D., McNeall, D. J. \& Dunstone, N. J. Importance of the deep ocean for estimating decadal changes in Earth's radiation balance. Geophysical Research Letters 38 (2011).

22. Palmer, M. \& McNeall, D. Internal variability of Earth's energy budget simulated by CMIP5 climate models. Environmental Research Letters 9, 034016 (2014).

23. Vernier, J.-P. et al. Major influence of tropical volcanic eruptions on the stratospheric aerosol layer during the last decade. Geophysical Research Letters 38 (2011).

24. Hansen, J., Sato, M., Kharecha, P. \& Schuckmann, K. v. Earth's energy imbalance and implications. Atmospheric Chemistry and Physics 11, 13421-13449 (2011).

25. Vernier, J.-P., Thomason, L. \& Kar, J. CALIPSO detection of an Asian tropopause aerosol layer. Geophysical Research Letters 38 (2011).

26. Trenberth, K. E. \& Fasullo, J. T. An apparent hiatus in global warming? Earth's Future 1, 19-32 (2013).

27. Chen, X. \& Tung, K.-K. Varying planetary heat sink led to global-warming slowdown and acceleration. Science 345, 897-903 (2014).

28. Maher, N., Gupta, A. S. \& England, M. H. Drivers of decadal hiatus periods in the 20th and 21st centuries. Geophysical Research Letters 41, 5978-5986 (2014).

29. Pan, Y. H. \& Oort, A. H. Global climate variations connected with sea surface temperature anomalies in the eastern equatorial pacific ocean for the 1958-73 period. Monthly Weather Review 111, 1244-1258 (1983). 
30. Trenberth, K. E., Caron, J. M., Stepaniak, D. P. \& Worley, S. Evolution of El Niño-Southern Oscillation and global atmospheric surface temperatures. Journal of Geophysical Research: Atmospheres (1984-2012) 107, AAC-5 (2002).

31. Morice, C. P., Kennedy, J. J., Rayner, N. A. \& Jones, P. D. Quantifying uncertainties in global and regional temperature change using an ensemble of observational estimates: The HadCRUT4 data set. Journal of Geophysical Research: Atmospheres (1984-2012) 117 (2012).

32. Hansen, J., Ruedy, R., Sato, M. \& Lo, K. Global surface temperature change. Reviews of Geophysics 48 (2010).

33. Smith, T. M., Reynolds, R. W., Peterson, T. C. \& Lawrimore, J. Improvements to noaa's historical merged land-ocean surface temperature analysis (1880-2006). Journal of Climate 21, 2283-2296 (2008).

34. Rayner, N. et al. Global analyses of sea surface temperature, sea ice, and night marine air temperature since the late nineteenth century. Journal of Geophysical Research: Atmospheres (1984-2012) 108 (2003).

35. Forster, P. M. et al. Evaluating adjusted forcing and model spread for historical and future scenarios in the CMIP5 generation of climate models. Journal of Geophysical Research: Atmospheres 118, 1139-1150 (2013).

36. Hyndman, R. \& Khandakar, Y. Automatic time series forecasting: The forecast package for R. Journal of Statistical Software 26 (2008). 
Acknowledgements We acknowledge the World Climate Research Programme's Working Group on Coupled Modelling, which is responsible for CMIP, and we thank the climate modelling groups (listed in Table S1) for producing and making available their model output. For CMIP the US Department of Energy's Program for Climate Model Diagnosis and Intercomparison provides coordinating support and led development of software infrastructure in partnership with the Global Organization for Earth System Science Portals. We thank Ian Edmond and Jamie Kettleborough for helping download and archive CMIP5 climate model data and Ed Hawkins for useful discussions. This work was supported by the Joint DECC/Defra Met Office Hadley Centre Climate Programme (GA01101) and represents a Met Office contribution to the Natural Environment Research Council DEEP-C project NE/K005480/1.

Competing Interests The authors declare that they have no competing financial interests.

Correspondence Correspondence should be addressed to C.D.R. (email: chris.roberts@ metoffice.gov.uk). 
Figure 1 (a) Global mean surface temperature (GMST) anomalies in observational data sets (red; see methods for details), CMIP5 historical + rcp4.5 scenario ensemble members (grey) and CMIP5 historical + rcp4.5 single-model ensemble means smoothed with a 10-year low-pass filter (blue). (b) Range (observations) and 5th - 95th percentiles (CMIP5 models) of rolling 10-year trends in GMST for the data sets plotted in (a).

Figure 2 (a) Multi-model probability of GMST trends due to internal variability less than or equal to the specified values (all models). For example, the probability of a -0.25 $\mathrm{K} /$ decade trend lasting 10 years is about $0.05(5 \%)$. This probability drops to about 0.01 (1\%) for trend length of 14 years. (b) Conditional probability of GMST trends continuing 5 more years, given the existence of a trend in the preceding $\mathrm{N}$ years. For example, if a $-0.25 /$ decade trend has been observed for 12 years, the probability of it continuing for another 5 years is about $0.10(10 \%) .(c+d)$ Same as $(a+b)$, but calculated using the observationally-constrained subset of models identified in table S1/Figure 3.

Figure 3 (a) Relationship between decadal sea surface temperature (SST) trends in the Niño 3.4 region $\left(120^{\circ} \mathrm{W}-170^{\circ} \mathrm{W}\right.$ and $\left.5^{\circ} \mathrm{S}-5^{\circ} \mathrm{N}\right)$ and decadal GMST trends in CMIP5 preindustrial control simulations (labels correspond to models in table S1). (b) The magnitude of Niño 3.4 SST variability on annual and decadal time scales in CMIP5 preindustrial control simulations compared with observed values (see methods). Our constrained ensemble corresponds to the nine models that simulate the magnitude of Niño 3.4 variability on interannual to decadal time scales to within $\pm 20 \%$ of observed values 
Figure 4 (a) Trends in upper ocean heat content (UOHC, 0-100m), deep ocean heat content (DOHC, 100m-bottom), total Earth system energy content (defined as time-integrated anomalies in top-of-atmosphere radiation fluxes, TOA), and the PDO index for 'hiatus', 'continued hiatus', and 'accelerated warming' periods as defined in the main text. Error bars indicate \pm 1 s.d. across the composite. $(c+d)$ Composite mean patterns of nearsurface temperature change associated with 5-year 'continued hiatus' ( $<-0.2$ K.decade, $\mathrm{N}=10$ ) and 'accelerated warming' ( $>0.2 \mathrm{~K} /$ decade, $\mathrm{N}=25$ ) periods following 'hiatus' decades $(<-0.2 \mathrm{~K} /$ decade, $\mathrm{N}=61)$ in our constrained ensemble. To indicate consensus across composites, data are only plotted if more than $2 / 3$ of trends are of the same sign. Further details are included as supplementary material. 
Table 1: Selected absolute and conditional probabilities extracted from figure 2 for trends in GMST sufficient to offset a warming rate of $0.2 \mathrm{~K} /$ decade. Values are given as multimodel means with the range across models in parentheses.

\begin{tabular}{lll}
\hline & All CMIP5 models & Constrained ensemble \\
\hline 5 years & $0.28(0.15-0.33)$ & $0.30(0.27-0.33)$ \\
10 years & $0.09(0.00-0.17)$ & $0.10(0.05-0.17)$ \\
20 years & $<0.01(0.00-0.02)$ & $<0.01(0.00-0.02)$ \\
5 years (following an existing 15-year hiatus) & $0.16(0.00-0.29)$ & $0.15(0.00-0.25)$ \\
\hline \hline
\end{tabular}


(a) Global mean surface temperature (GMST) anomalies
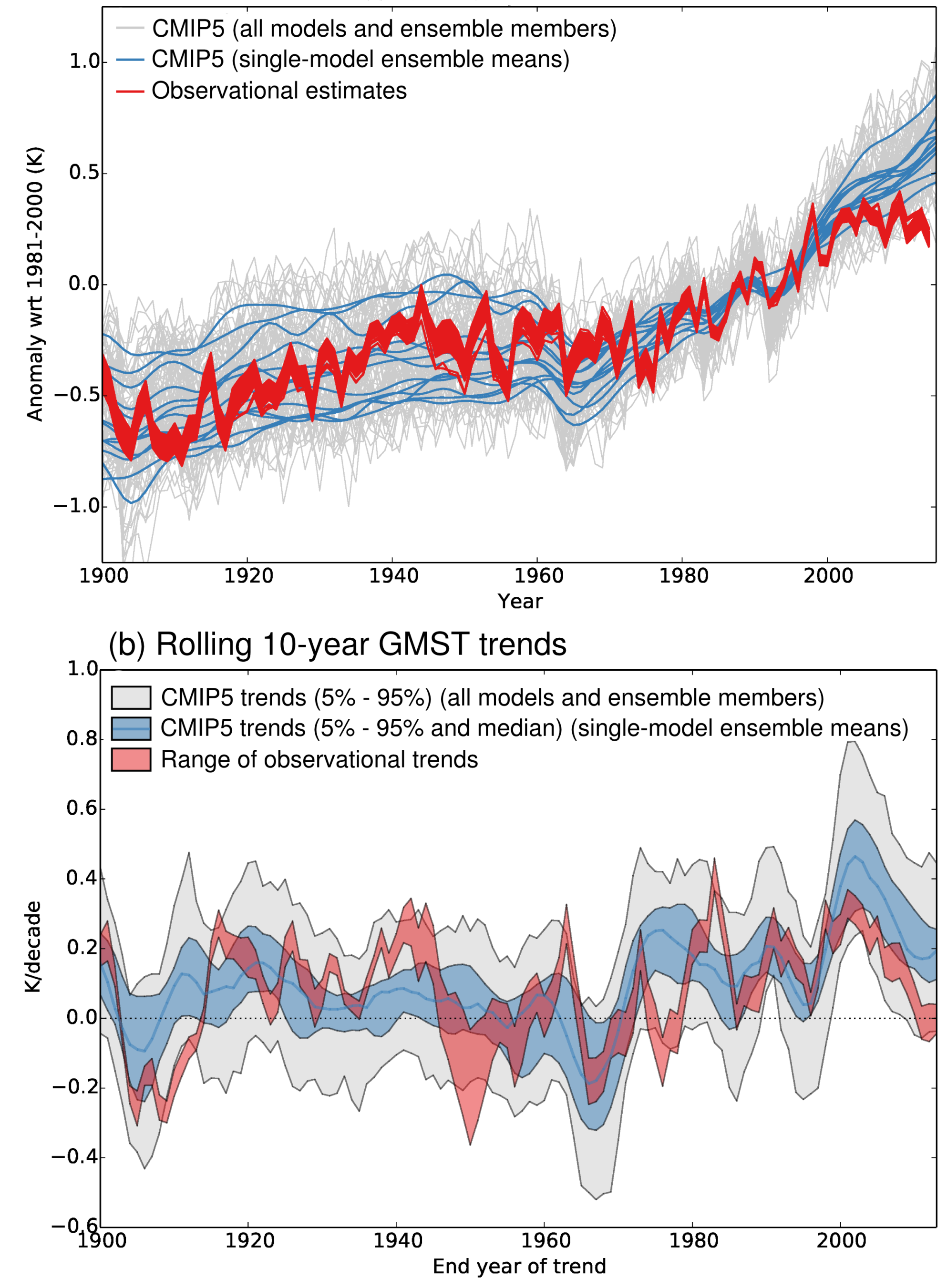
(a) Probability of GMST trends due to internal variability (all models)

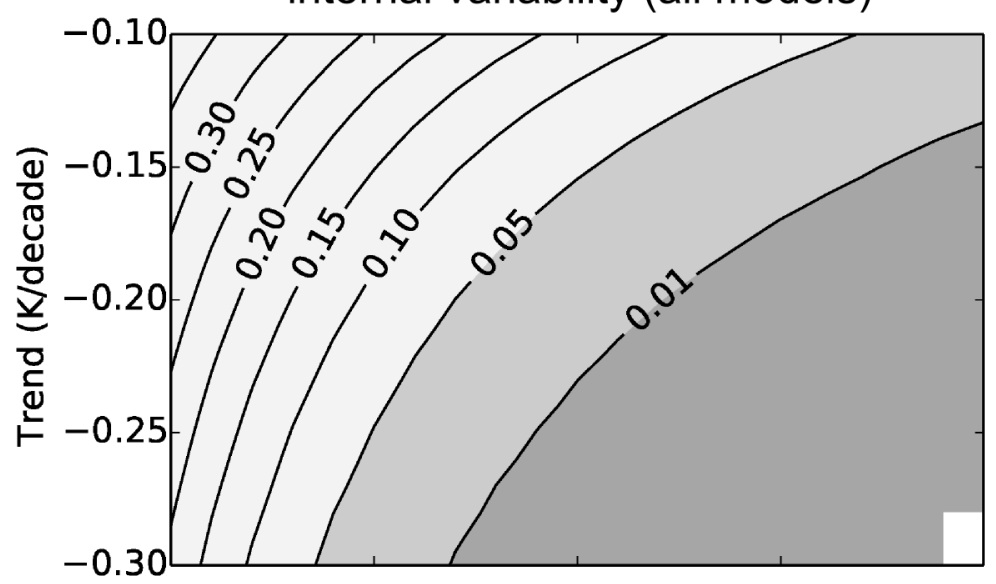

(c) Probability of GMST trends due to internal variability (constrained ensemble)

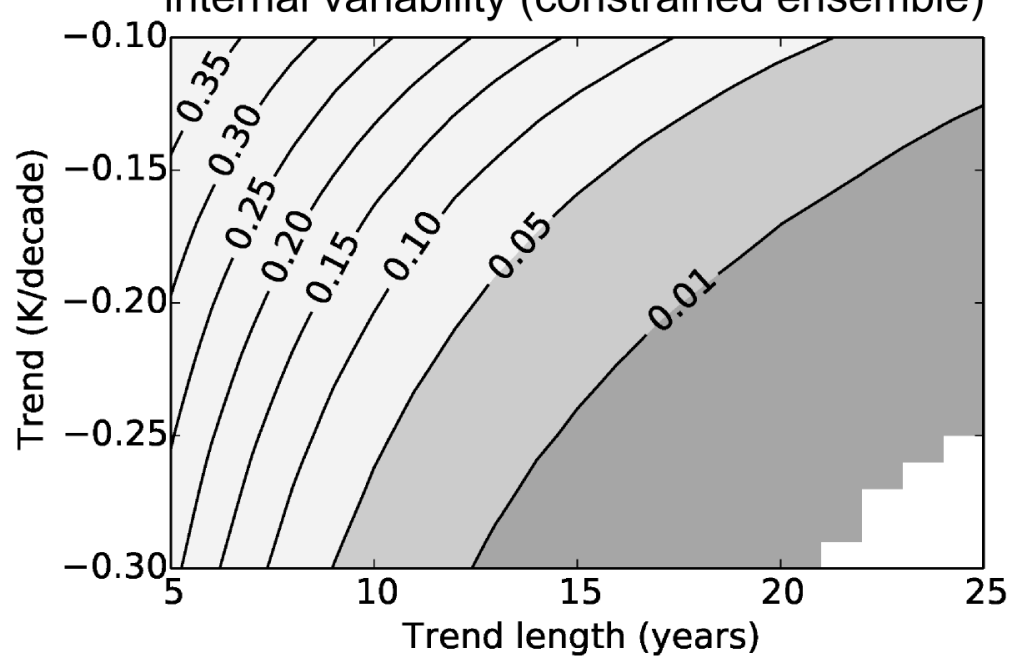

(b) Probability of GMST trend continuing 5 more years (all models)

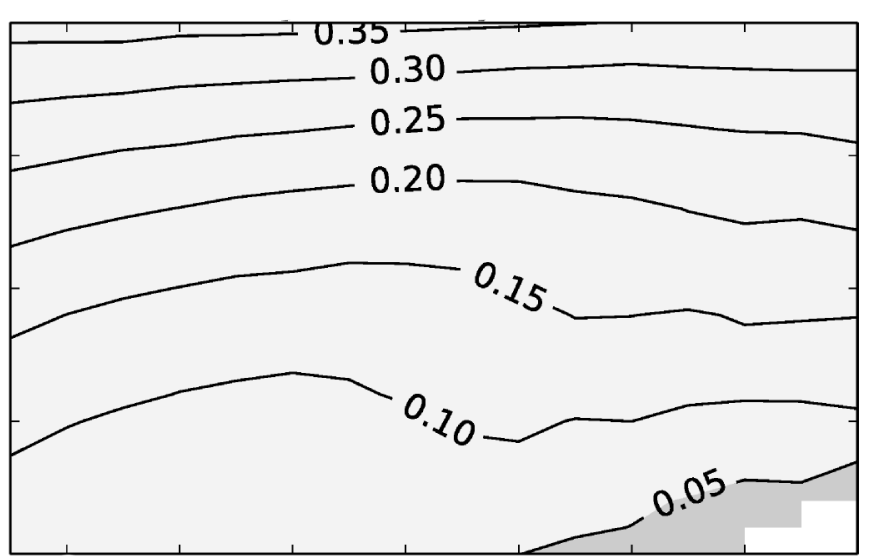

(d) Probability of GMST trend continuing 5 more years (constrained ensemble)

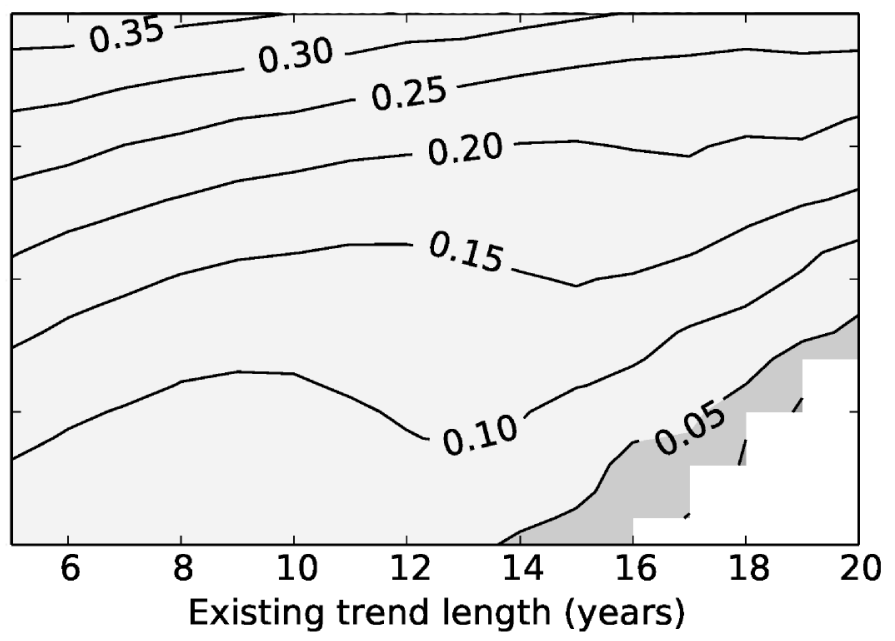


(a) Relationship between decadal variations in GMST and Niño 3.4 index in CMIP5 models
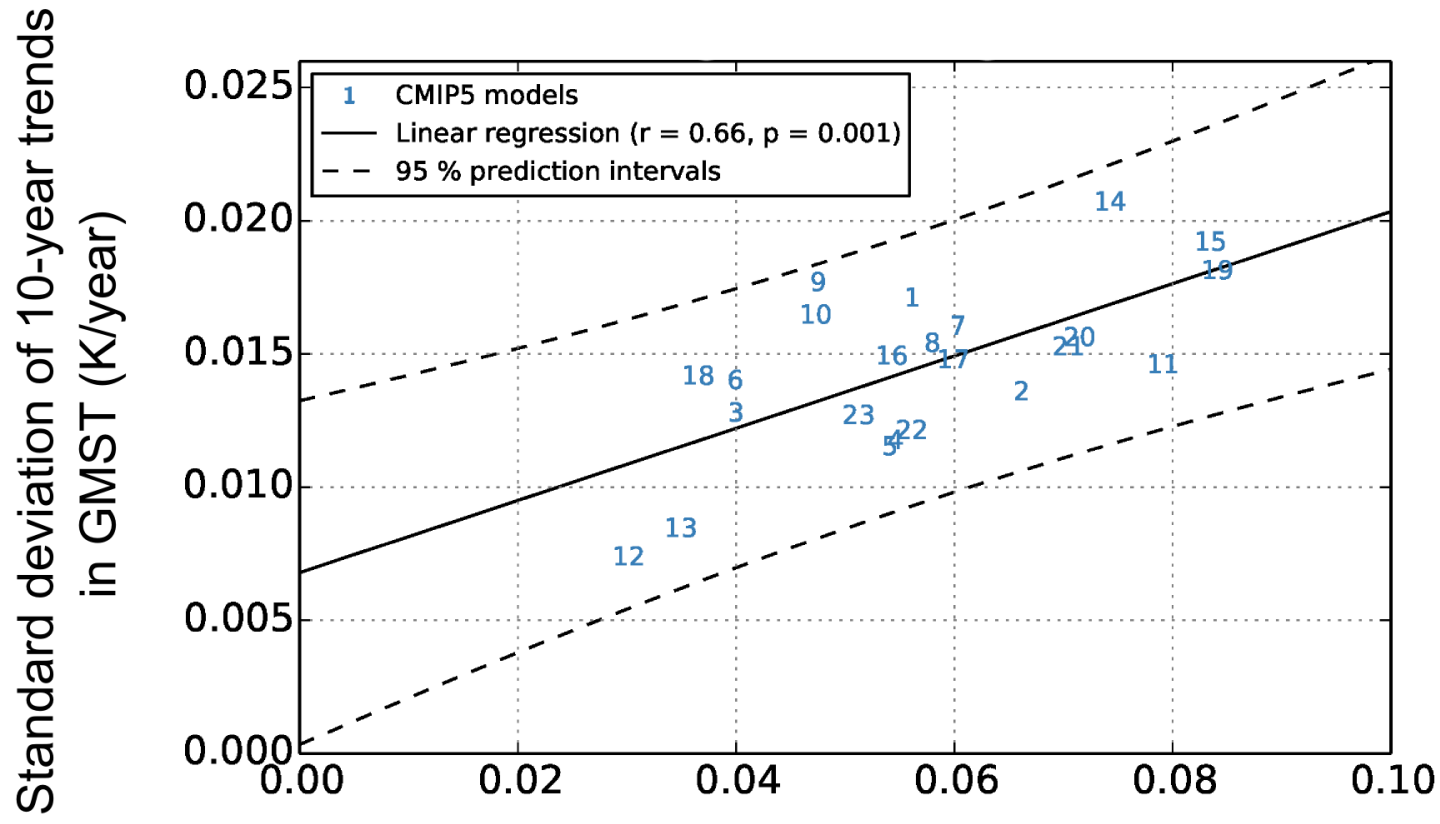

Standard deviation of 10-year trends in Niño 3.4 index (K/year)

(b) Observational constraint applied to Niño 3.4 index

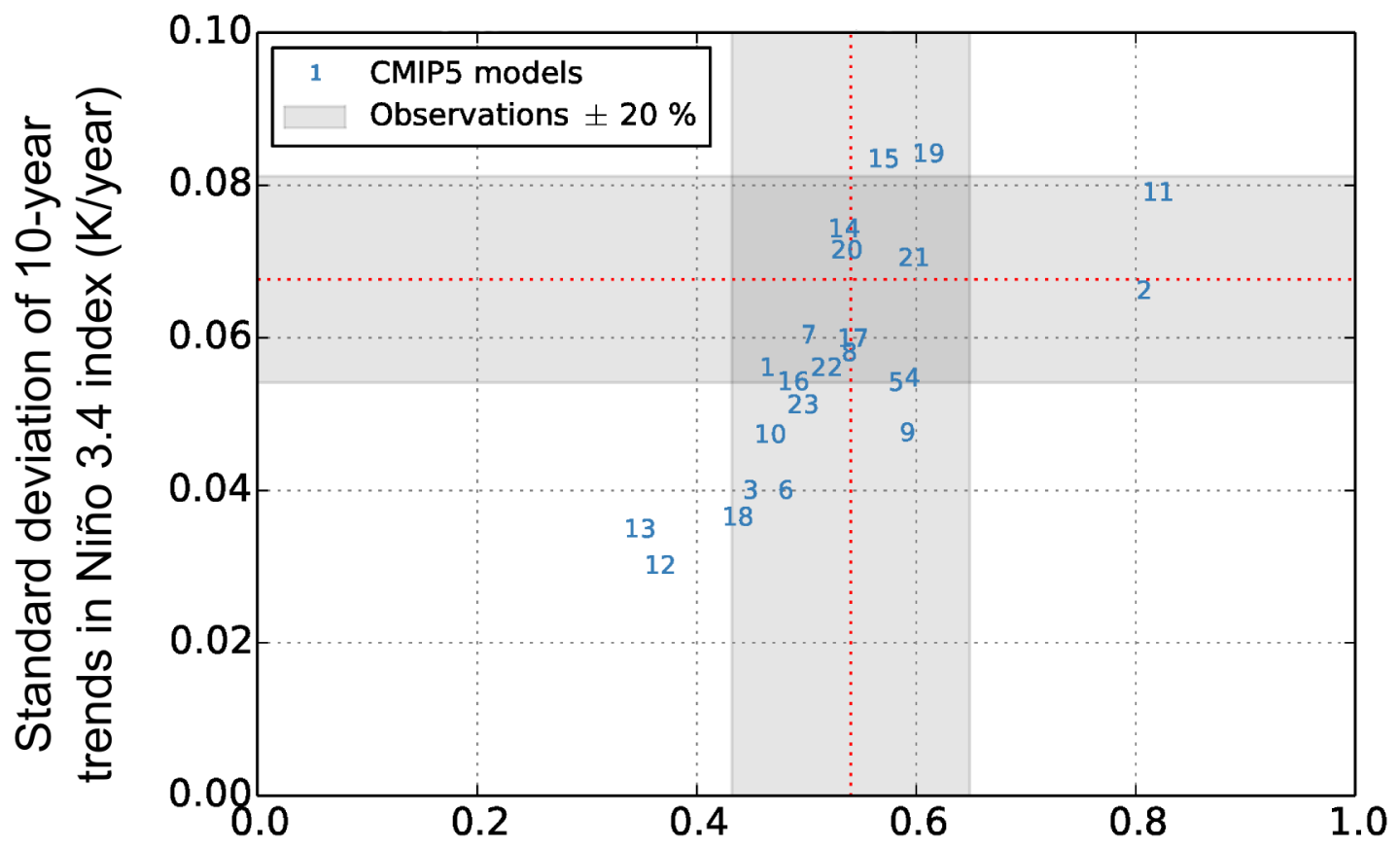

Standard deviation of annual Niño 3.4 index (K) 
(a) Trends in energy content and PDO index

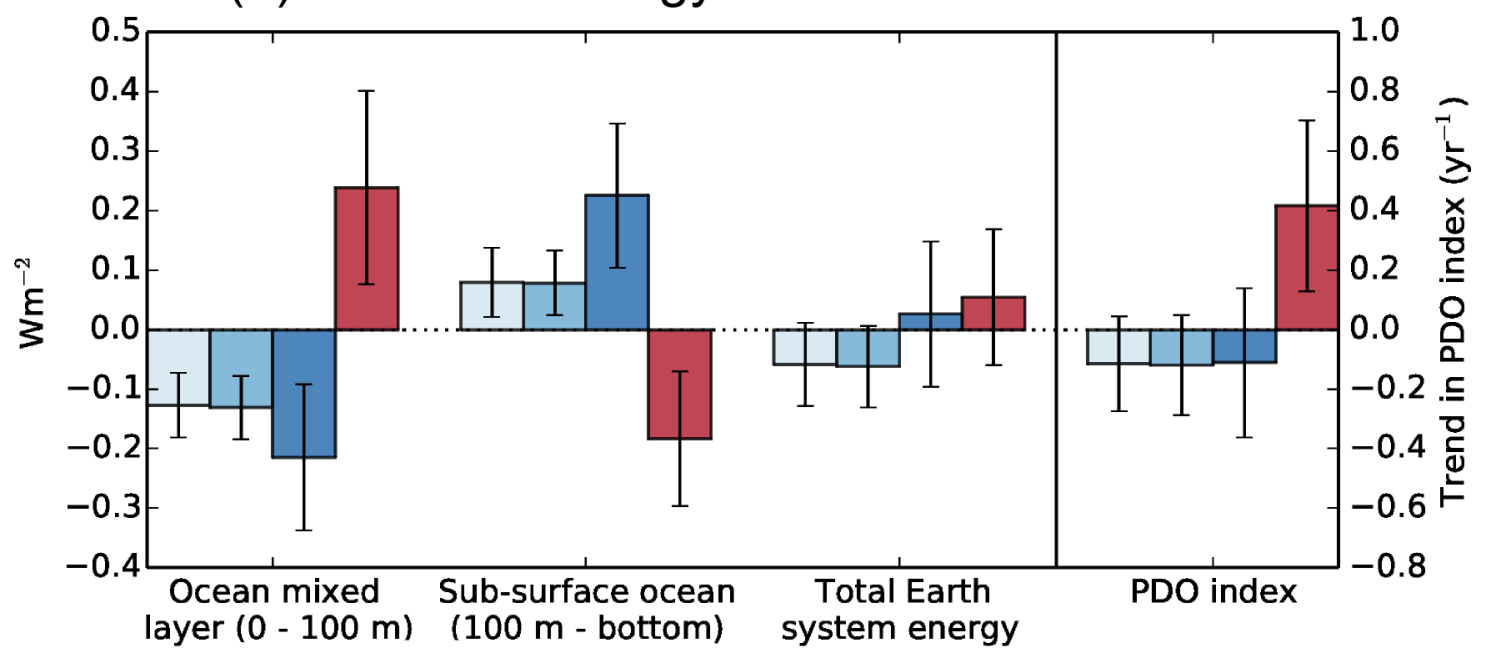

$\square$ 10-year "hiatus" periods in all models (GSMT trends $\leq-0.2 \mathrm{~K} /$ decade)

10-year "hiatus" periods in constrained ensemble (GSMT trends $\leq-0.2 \mathrm{~K} /$ decade)

5 -year "continued hiatus" periods (GSMT trends $\leq-0.2 \mathrm{~K} /$ decade)

5 -year "accelerated warming" periods (GSMT trends $\geq 0.2 \mathrm{~K} /$ decade)

(b) Distribution of 5-year GMST trends due to internal variability

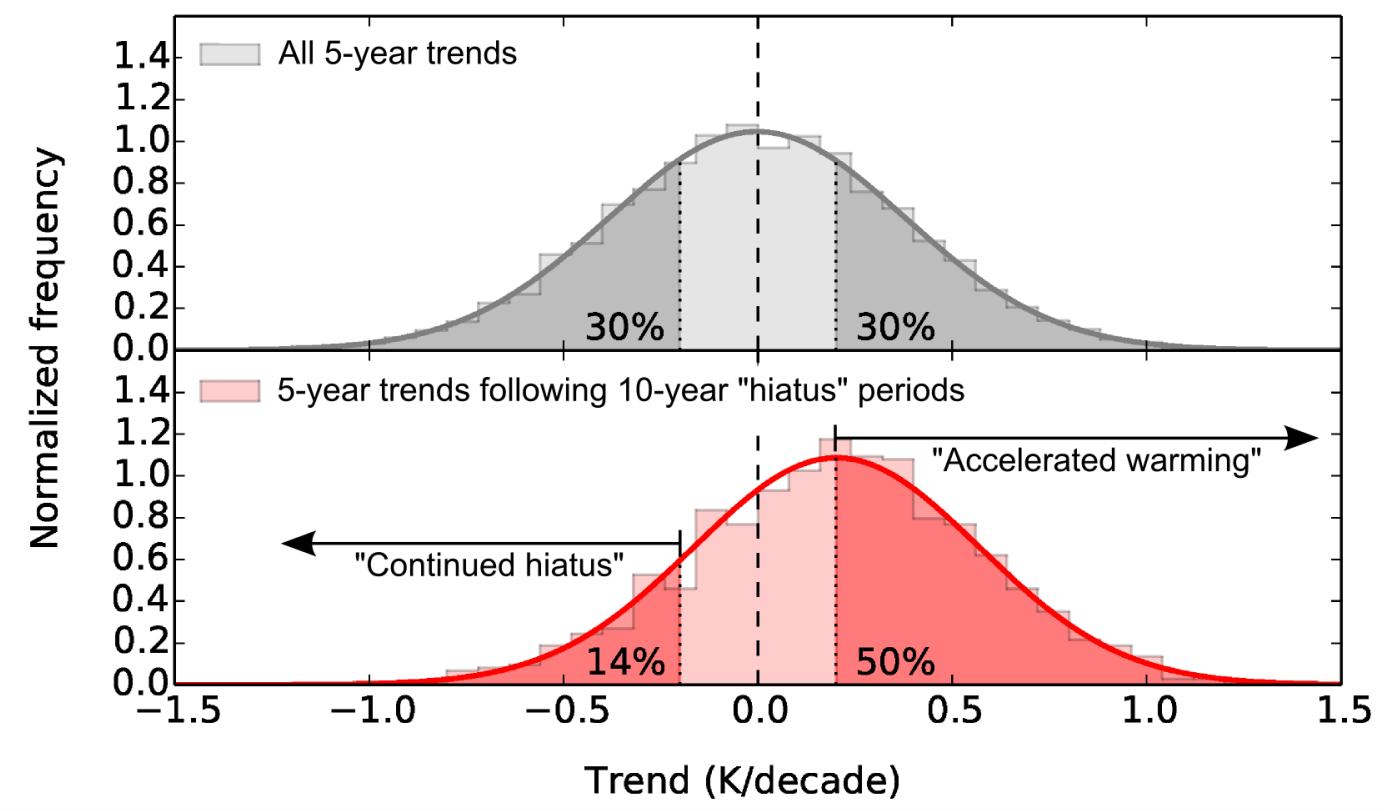

(c) Composite mean surface temperature trends during 5-year "continued hiatus" periods

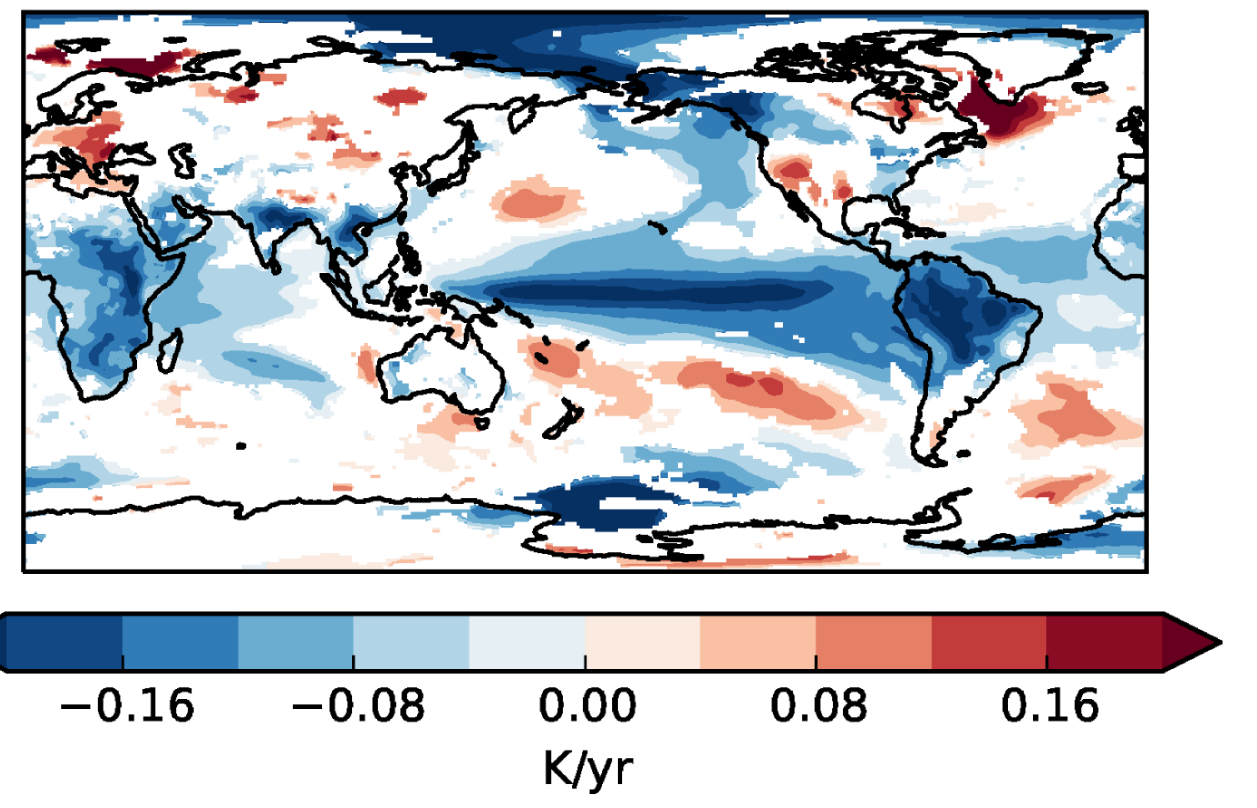

(d) Composite mean surface temperature trends during 5-year "accelerated warming" periods

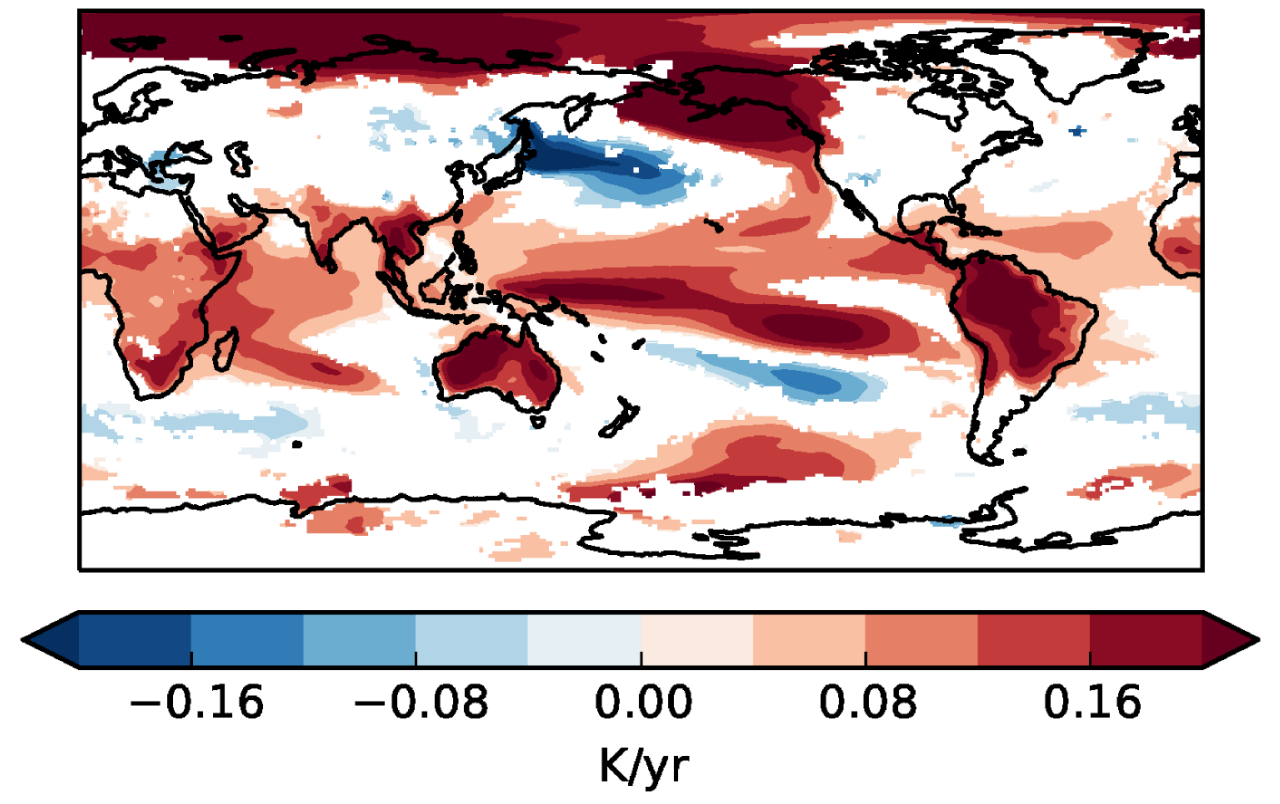

